\title{
EFFECTIVENESS OF THE IMPLEMENTATION OF THE MECHANISATION PROGRAMME FOR EMERGING FARMERS IN THE OVERBERG AND EDEN DISTRICTS OF THE WESTERN CAPE
}

\author{
Bastian, R. M. ${ }^{1}$, Swanepoel, J. W. ${ }^{2}$ and Van Niekerk, J. A. ${ }^{3}$ \\ Correspondence author: R. Bastian. Mail: ReneB@elsenburg.com
}

\begin{abstract}
Agricultural mechanisation has received increased interest during the last decade for the development of agriculture in African countries. One of the challenges of mechanisation in farming is the high cost associated with the procurement and maintenance of tractors and implements. Therefore, a mechanisation programme to assist with the development of emerging farmers in the country was established. The study was undertaken to determine the effective implementation of the mechanisation programme from the perspectives of farmers and extension officers. The study aimed to investigate whether the programme has assisted with the development of emerging farmers and whether the current implements in centres are suitable for the various commodities produced per area. To meet the objectives of this study, structured questionnaires were administered to participants and interviews were conducted with stakeholders in management positions. The findings revealed that the efficiency of the mechanisation programme can be improved upon, as farmers highlighted challenges that included access to mechanisation centres, the correct type and availability of implements. Nevertheless, the mechanisation programme has had a positive impact on the development of emerging farmers, and they feel that if issues are addressed, the programme could be even more beneficial in ensuring that recipients of the programme reap maximum benefits.
\end{abstract}

Keywords: Emerging farmers, Extension, Mechanisation

\section{INTRODUCTION}

Mechanisation is a key component in increasing agricultural crop production and enhancing food security, especially in developing countries (Mrema, Soni \& Rolle, 2014). Various benefits exist through implementing mechanisation in agricultural production. These benefits include increased production, efficiency of labour and yields, lower unit costs, and enhanced agricultural techniques. It may also lead to commercial agriculture where it could contribute to improved land utilisation and subsequent increases in farm income (Sims, Hilmi \& Kienzle, 2016). This can be achieved through timeous planting, pest and weed control, accurate application of fertilizer, and harvesting (Rai et al, 2011). In addition, mechanisation can add to the growth of value adding in agriculture, as it can be utilised for processing, marketing undertakings, as well as transport of produce after harvesting (Sims et al, 2016). The use of sustainable agricultural mechanisation can also play a role in conserving resources, as farmers are now able to employ conservation agricultural practices with the availability of tractors and implements.

\footnotetext{
${ }^{1}$ Western Cape Department of Agriculture, Elsenburg, Western Cape, +27 (0)28 4254819.

${ }^{2}$ Senior Lecturer, Centre for Sustainable Agriculture, Faculty of Natural and Agricultural Sciences, University of the Free State, Bloemfontein, +27 (0)51 401 2163, SwanepoelJW@ufs.ac.za.

${ }^{3}$ Director, Centre for Sustainable Agriculture, PO Box 339, Bloemfontein 9300, Republic of South Africa.
} 
South Africa has a diverse agricultural sector, where commercial farmers flourish within their farming operations, yet in another sector, which includes smallholders, farms are still in the developing stage and growing in order to run sustainable farming businesses. Agriculture plays a vital role in the economy of South Africa and also contributes to job creation, land reform and rural development, decreasing poverty, and increasing food security in the country. A study conducted in 2003 showed that South Africa has over 325000 tractors, where ownership of these tractors consisted of over $80 \%$ commercial farmers (Simalenga, Joubert \& Hanekom, 2003). Furthermore, $77 \%$ of potentially arable land suitable for farming is currently under production and the optimisation of agricultural mechanisation can play a vital role to expand this area and also to increase the use of existing agricultural land (Houmy et al, 2013). Emerging farmers can definitely benefit by the incorporation of mechanisation in their farming activities and it can attribute to many benefits as previously discussed. The increase in productivity is one of these benefits and can be achieved by timeous planting, pest and weed control, accurate application of fertilizer, and harvesting (Rai et al, 2011). Some of the challenges that exist with implementation of mechanisation in developing countries also affects farmers in South Africa. The main challenge is the availability of funding to invest in mechanisation, as well as a lack of skill.

Through these challenges, the importance of the concept of mechanising agriculture has been recognised by the South African government in the development of smallholder production, and the Department of Agriculture, Forestry and Fisheries (DAFF) has initiated a mechanisation programme to assist emerging farmers. The development of emerging farmers is important to assist in reducing poverty and contributing to food security and the emerging farmer sector in our country is critical in terms of human welfare, job creation and political stability (Delgado et al., 2001). This is why the South African government has been spending a substantial amount of its budget towards supporting emerging farmer development (Moloi, 2010). Originally launched in $2010 / 11$, the project was initially only implemented in a few provinces. The official launch of the programme in the Western Cape took place in 2013 (DAFF, 2013).

The effectiveness of the implementation of mechanisation programmes in the country has become an issue throughout the country. The perception of its implementation from farmers, extension officers and management was investigated in different districts in the Western Cape to ascertain whether the mechanisation programme is effective and has assisted with the development of emerging farmers. Furthermore, the study aimed to determine whether the implementation of the mechanisation programme has assisted with the development of emerging farmers. It also aimed to determine if the current implements in mechanisation centres are suitable for agricultural production for the various commodities produced per area.

\section{METHODOLOGY}

The area of research chosen was the Overberg and Eden Districts of the Western Cape Province. Both these districts have rich agricultural sectors that contribute to the respective district's gross domestic product (GDP), where agriculture contributes $11.2 \%$ to Overberg's GDP (Western Cape Government (WCG), 2015a) and 6.2\% to Eden's GDP (WCG, 2015b). A mixed-method research design was incorporated for the study that consists of both qualitative and quantitative research and analysis. Structured questionnaires were designed for emerging farmers in the Overberg and Eden districts that make use of mechanisation as part of their 
farming enterprises. Additionally, extension officers that work closely with emerging farmers in the entire Western Cape Province were recruited to complete questionnaires. As part of the qualitative portion of the study, interviews were conducted with district managers for the Overberg and Eden Districts, as well as management for some of the mechanisation centres to gather information from these individuals and their perspectives with regards to the implementation of the mechanisation programme.

The questionnaires administered to farmers gave an indication of their perception with regards to the mechanisation programme, and impacts on their farming businesses. The questionnaires administered to extension officers allowed triangulation of data collected from the farmers. Extension officers work closely with the farmers and may be able to supply additional information regarding mechanisation in the emerging farmer sector, which may be unintentionally omitted by the farmers, as well as providing a different perspective in relation to the mechanisation programme implementation. A sample of 31 farmers was selected to complete questionnaires, while 30 extension officers were consulted for the study. The district managers and two managers from the mechanisation centres were interviewed as part of the study and their responses are included in the discussion of the results.

\section{RESULTS AND DISCUSSION}

\subsection{Demographics}

Of the 31 farmers that took part in the study, $16 \%$ were female, while $84 \%$ of the farmers were male. This is synonymous of farming in South Africa, where agriculture is predominantly male orientated. Figure 1 portrays the range in age of the various farmers. It must be noted that of the 31 farmers that took part in the study, the majority of the farmers $(71 \%$ or 23 farmers in total) were over the age of 40. This is rather concerning as the involvement of youth in agriculture is key to ensuring growth in the economy, job creation and contribution to food security. Brown (2012) stated that youth are the future of the agricultural sector due to the rapid growth of the world population and the waning in agricultural productivity paired with the increased migration to urban areas.

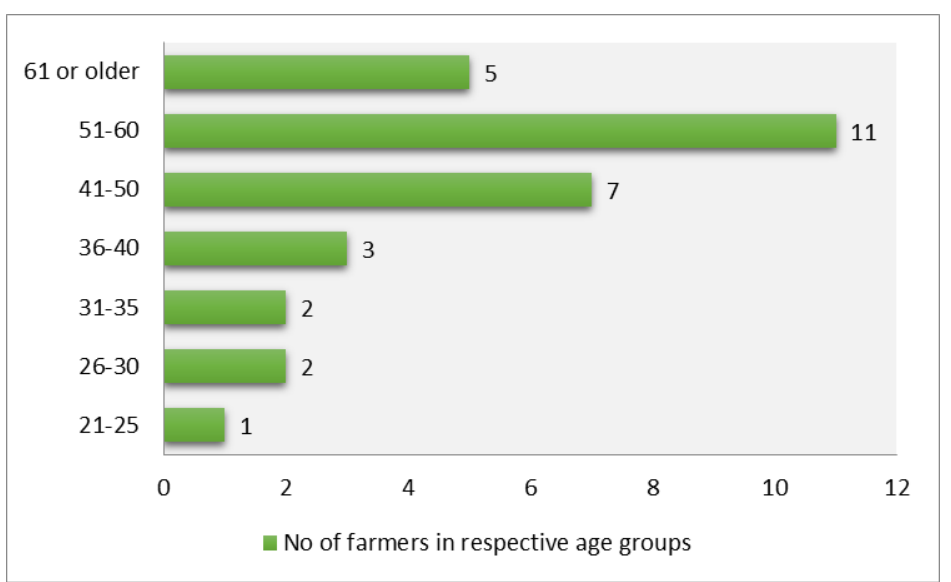

\section{Figure 1: Number of farmers in respective age groups}

With regards to the level of education of the farmer participants, $45.2 \%$ of the farmers had gained matric or higher qualifications, where $19.4 \%$ matriculated, $9.7 \%$ completed a national certificate, and $16.1 \%$ have other tertiary qualifications. As farming productively has various aspects that need to be taken into consideration, such as financial, technical and social facets, 
the fact that the majority of these farmers have some form of an educational background will contribute to a better understanding of innovations and developments with all issues relating to the agricultural sector. Farmers were asked to indicate their experience in farming, and as shown in Figure 2, the majority of farmers have more than 10 years' experience.

\section{Experience in farming}
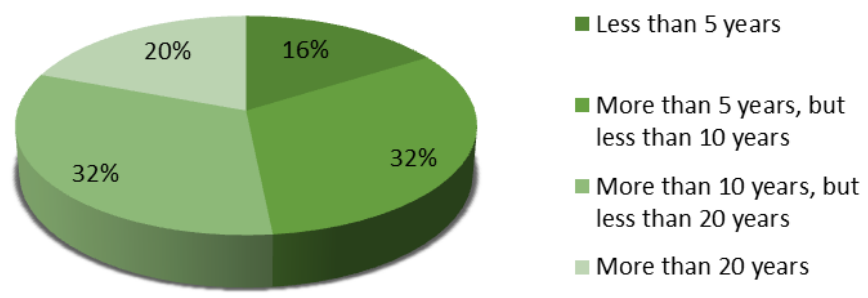

\section{Figure 2: Farming experience of participants}

The main commodities produced by participating farmers in the Overberg and Eden Districts were cattle production $(67.7 \%)$, sheep production $(51.6 \%)$, vegetable production $(25.8 \%)$, and grain production $(32.3 \%)$. Emerging farmers in the two districts have various land tenure arrangements as shown in Table 1, but only $32.2 \%$ of farmers own their farming land. The rest of the farmers have to access farming land through private or municipal leases, have access to commonage land, or were assisted by government and awarded with land from the Proactive Land Acquisition Strategy (PLAS) or Financial Assistance Land (FALA).

\section{Table 1: Land tenure arrangements of farmers}

\begin{tabular}{|l|r|r|}
\hline \multicolumn{2}{|c|}{ Land ownership } & Percentage (\%) \\
\hline Own land & Frequency & 10 \\
\hline Lease private land & 2 & 32.3 \\
\hline Leased municipal land & 8 & 6.5 \\
\hline PLAS/FALA land & 2 & 25.8 \\
\hline Commonage land & 7 & 6.5 \\
\hline Own land + lease private land + Leased municipal land & 1 & 22.6 \\
\hline Own land + Lease private land & 1 & 3.2 \\
\hline Total & 31 & 3.2 \\
\hline
\end{tabular}

The gender of the 30 extension officers that took part in the study was $63.3 \%$ male and $36.7 \%$ female and indicates that, where in previous years mainly male extension officers were appointed, females now also show interest in the field of extension and are employed by government institutions. The extension officers' ages were as follows: $3.3 \%$ were 20-30 years; $43.3 \%$ were $31-40$ years; $40 \%$ were $41-50$ years, and $13.3 \%$ were older than 50 years. This also links to the extension experience of the participants as indicated in Table 2, where 24 extension officers specified that they have seven or more years' experience in providing extension advice. 


\section{Table 2: Number of years of extension experience of extension officers}

\begin{tabular}{|l|r|r|}
\hline \multicolumn{3}{|c|}{ Extension advisory experience } \\
\hline & Frequency & \multicolumn{1}{|c|}{ Percentage (\%) } \\
\hline 1 to 3 years & 5 & 16.7 \\
\hline 4 to 6 years & 1 & 3.3 \\
\hline 7 to 9 years & 7 & 23.3 \\
\hline$>10$ years & 17 & 56.7 \\
\hline Total & 30 & 100.0 \\
\hline
\end{tabular}

The extension officers also indicated that they provide extension advice to farmers in various commodities within the Western Cape Province, which included grain and pastures, livestock (cattle, sheep, pigs, goats and poultry), vegetables, fruit, viticulture, fynbos, honey bush tea and bees.

\subsection{Role of the mechanisation programme in the development of emerging farmers}

Farmers indicated that $83.9 \%$ of them make use of implements as part of their farming enterprises, and Figure 3 shows the different types of implements that are utilised by these farmers. This information corresponds to the answers provided by extension officers, where 93.3\% of them indicated that their farmers used implements. With regards to ownership of implements, the farmers indicated that only $51.6 \%$ of them owned the implements they use, and it also parallels the sentiments of extension officers regarding farmers owning implements, where $46.7 \%$ indicated that their farmers owned implements. These results showed that many farmers lack the mechanisation needed to farm and shows that the emerging farmers have a need for assistance with regards to mechanisation.

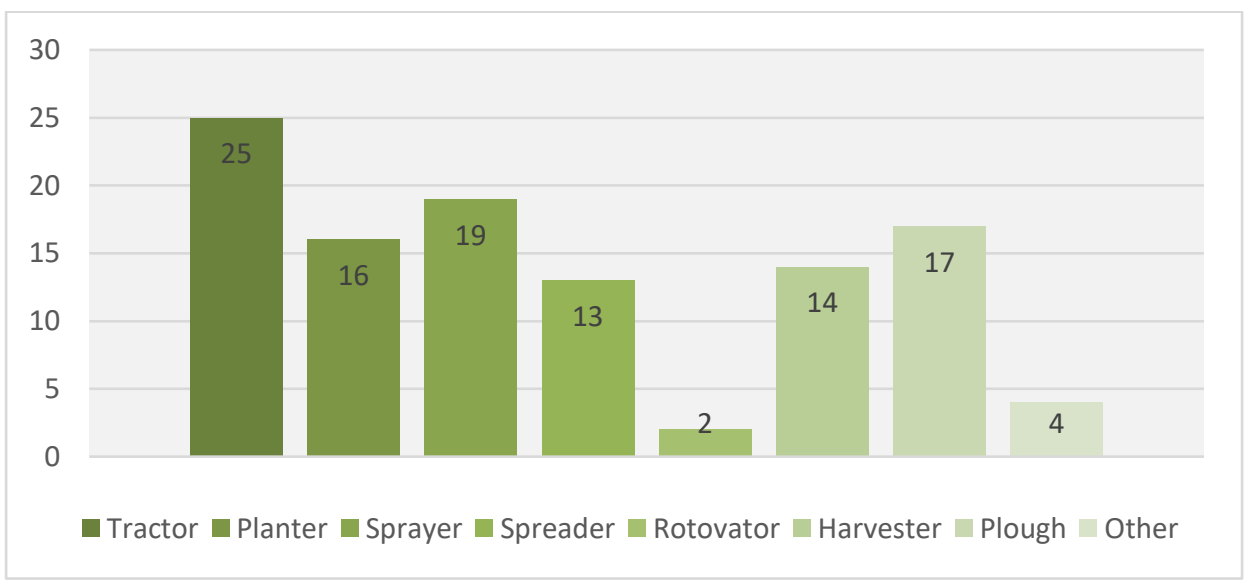

Figure 3: Implements used by farmers

Farmers indicated that they gained implements by hiring them from private companies or other farmers, using contractors or using implements supplied by the mechanisation programme at mechanisation centres. The mechanisation programme was implemented to address the need for mechanisation for emerging farmers in the country. When farmers were asked if the mechanisation programme has assisted them with the development of their farming businesses, $45 \%$ indicated yes, $43 \%$ said no, while $13 \%$ opted not to answer the question as mechanisation centres were not available in their area. When the question was posed to extension officers regarding the effectiveness of the mechanisation for farmers in their respective areas, $54 \%$ said 
it was effective, while $43 \%$ said it was not. An additional $3 \%$ of extension officers did not have mechanisation centres in their area.

With regards to markets, only $18 \%$ of the farmers sell their produce to informal markets. The rest of the farmers all have either local or formal markets in place to which they have been able to sell their produce. More than $90 \%$ of farmers indicated that they have a profitable farming business. Of the farmers who were profitable, $69.6 \%$ reinvested profits in their farming enterprises, as can be seen in Figure 4. This result gives an indication that emerging farmers are eager to see their agricultural enterprises grow and be sustainable in future, and can be an indication that there has been development within this farming sector.

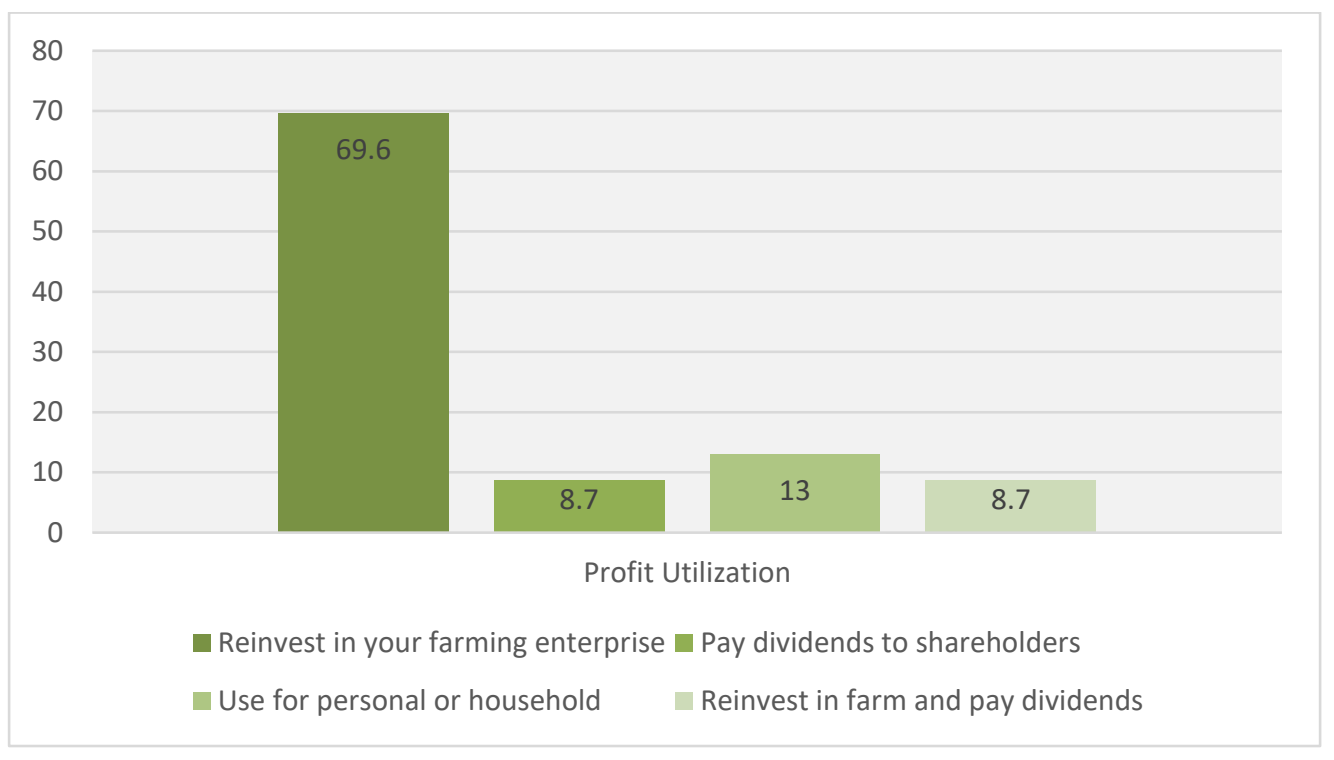

\section{Figure 4: Expenditure of farmers' profits}

Access to funding is one of the constraints that emerging farmers face that can also hamper the development in their farming enterprises (Senyolo et al, 2009). DAFF has launched many farmer support services to assist emerging farmers including the Comprehensive Agricultural Support Programme (CASP) (National Department of Agriculture (NDA), 2007). In the Western Cape Department of Agriculture (WCDoA), CASP was implemented through a commodity approach, and evaluations are done using Commodity Project Allocation Committees (CPACs). Farmers in the study were asked whether they have received any assistance from the WCDoA through the CPAC initiative, and $80.6 \%$ of farmers indicated that they have received governmental support through funding, while $19.4 \%$ did not receive any funding. Of the farmers that received funding, 52\% indicated that the funding they have received has been for mechanisation aspects within their farming businesses. The funding for mechanisation included procurement of various implements, as well as funding for contractors, as pointed out in Figure 5. 
S. Afr. J. Agric. Ext.

Vol. 47 No. 2, 2019: 58 - 71

http://dx.doi.org/10.17159/2413-3221/2019/v47n2a503

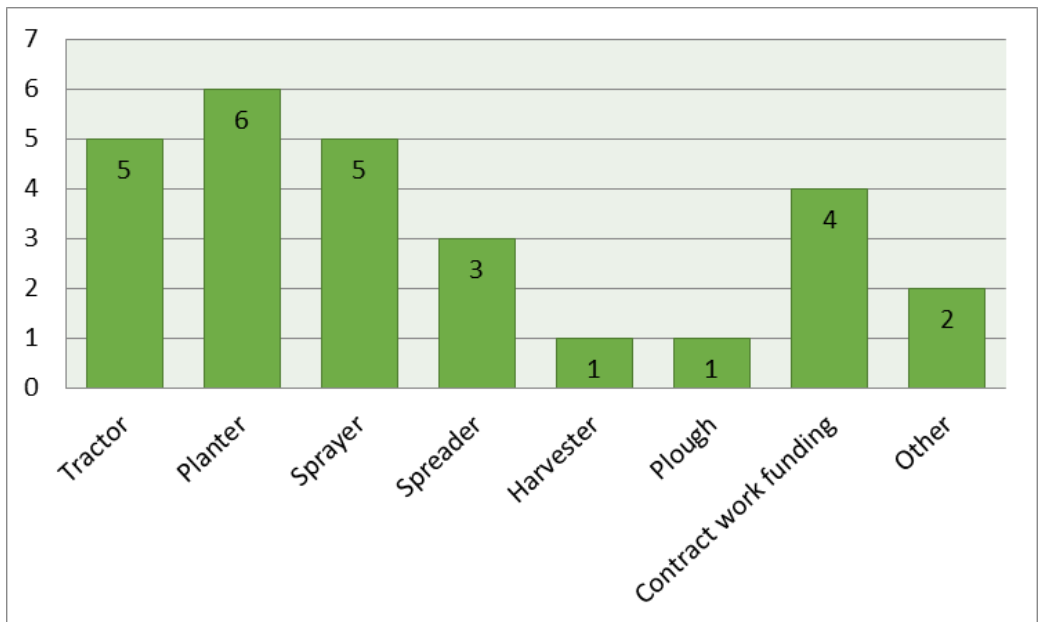

Figure 5: Mechanisation assistance received through governmental funding

This information shows that DAFF not only assisted emerging farmers with mechanisation through the mechanisation programme, but also through the CASP initiative.

With regards to training, farmers were also asked to indicate whether they have received training to operate machinery. Only $18 \%$ indicated that they have received training, while a further $11 \%$ indicated that they have received formal training, but already knew how to operate machinery. Those who have received training named the WCDoA, commodity organisations such as GrainSA, and implements manufacturers as organisations providing training to them. Of the farmers that have not received any training, $85.7 \%$ indicated that they would be interested in receiving training to operate machinery. The fact that many of the farmers also have mentors provides another avenue by which the farmers can receive training. Mentors can provide farmers with training to operate machinery, as well as assisting farmers to fix or maintain their machinery. Extension officers also indicated that $45 \%$ of the farmers in their areas could operate machinery, while $40 \%$ mentioned that it was dependent on the experience of the farmer. Extension officers further indicated that the WCDoA could provide training for the farmers to operate machinery. With regards to suggestions for improving the implementation of mechanisation centres, many of the extension officers acknowledged that training should be provided to drivers or operators to specifically operate the implements available at these centres. Training can therefore also be seen as an aspect that could contribute to farmer development.

\subsection{Suitability of implements at mechanisation centres}

The implementation of mechanisation centres was initiated to assist emerging farmers to cultivate land, as many farmers did not have the necessary implements. This was mainly due to the high cost of procuring and maintaining implements and tractors, as well as economies of scale, as many farmers do not own enough land to make buying implements a viable decision. It is very important that the proper implements are available to these farmers as it can influence the production of their farming enterprises. Here the suitability of implements at the centres will be discussed by means of analysing data gathered during the study. 
Of the farmers that were aware of the programme (29 farmers), only $31 \%$ indicated that the implements in the mechanisation centres are suitable or available when needed, while $53.3 \%$ of extension officers stated that the mechanisation centres were effective to assist farmers with their needs. Reasons for the participants' answers with regards to the use of mechanisation centres are indicated in Figure 6.

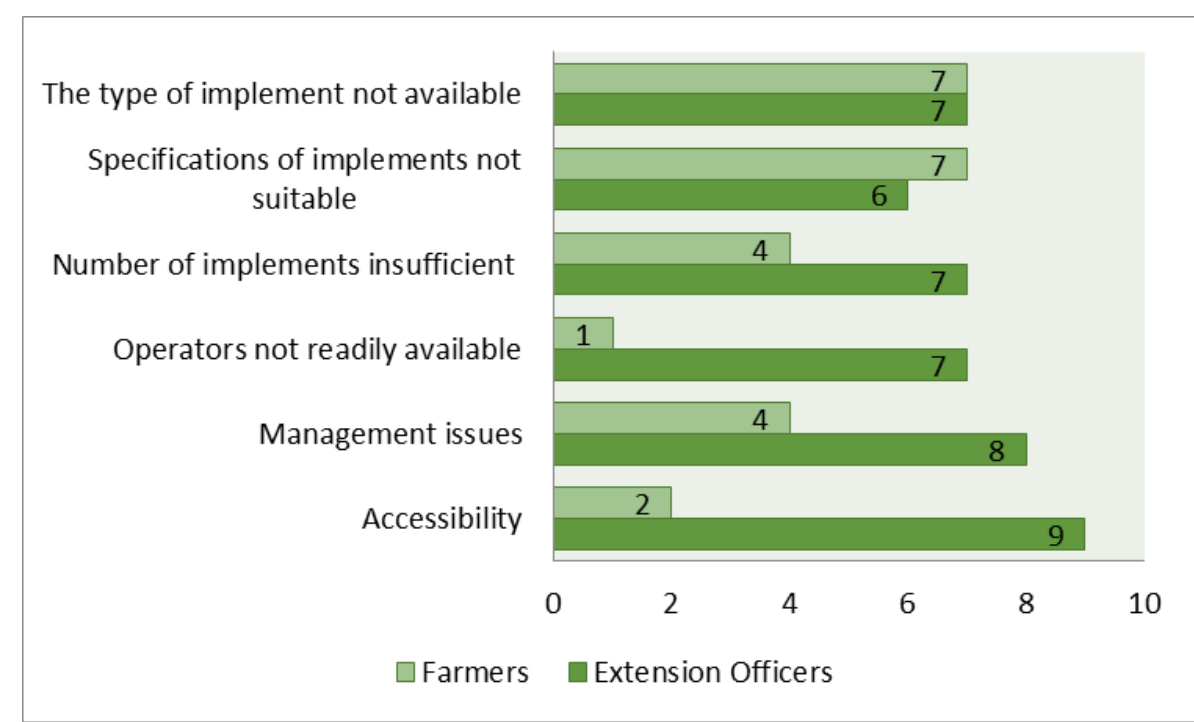

\section{Figure 6: Reasons for why the use of mechanisation centres are not always effective}

It can be seen that farmers mainly indicate that the type or specifications of the implements they need were not available, with the majority of extension officers naming accessibility as the main reason for ineffectiveness regarding the mechanisation programme. It must be kept in mind that the farmers that took part in the study were only from the Overberg and Eden Districts, while the extension officers were from the entire Western Cape Province, thus a comprehensive view with regards to the effectivity of mechanisation in the entire province, or even the country, is lacking.

There are 11 mechanisation projects in the Overberg District and 20 projects in the Eden District. Of the 11 projects in the Overberg District, four are mechanisation centres for the surrounding communities, while the remainder of the projects are individual emerging farmer projects that have received tractors or implements from the mechanisation programme. In the Eden District, eight projects are mechanisation centres and 12 are individual farming projects. It can be seen that there is a limited number of mechanisation centres in the two districts, compared to the number of farmers, which corresponds with the farmers' observation of the inaccessibility and limited amount of implements available for use. Management indicated that there was a need for more suitable implements, especially implements used to practice conservation agriculture (CA) techniques, such as no-till or minimum-till planters for grain producers. These implements are very expensive and emerging farmers do not have access to them.

It was furthermore indicated that the number of implements and its suitability for the various terrains and commodities are not always appropriate, but that those farmers who have access to the mechanisation centres have been able to increase productivity on their farms. Another 
issue raised is that the implements in the area are not sufficient to supply for the needs of farmers. Many grain farmers have been impacted negatively due to harvest losses as a result of swatters and harvesters not being available timeously. The shortage of implements also impacts these farmers during the planting season. As the implements are expensive, these farmers are dependent on mechanisation centres or hiring contractors, the latter of which are not always reliable with regards to timeous planting or harvesting periods. Managers of mechanisation centres highlighted that the main issue is the lack of implements available to supply the needs of farmers in the surrounding community.

Most of the centres had tractors available which the farmers can hire from the mechanisation centres. Other available implements include planters, ploughs, sprayers, fertilizer spreaders, and hammer mills. As previously mentioned, grain farmers in these areas indicated a need for minimum-till planters and other implements in order for them to practice CA techniques, which were also echoed my management. The conservation or increase of natural resources is imperative to ensure longevity in the agricultural sector, and the promotion of CA techniques to increase food production through sustainable farming techniques is at the forefront to achieving this (Corbeels et al, 2014). The three main principles to achieve CA are minimal soil disturbance, permanent soil cover, and crop rotation (Hobbs, 2007; Thierfelder, Mwila \& Rusinamhodzi, 2013). In order for farmers in developing countries to adopt these techniques, more emphasis needs to be placed on the increase in production and productivity it can offer instead of a means of saving resources (Andersson \& D'Souza, 2014). Emerging farmers in South Africa are also under pressure to introduce CA techniques into their farming practices, but it must be noted that these farmers, similar to other smallholder farmers in developing countries, have different socio-economic and agronomic situations that influence its implementation (Andersson \& D’Souza, 2014).

Extension officers that took part in the study were asked to indicate whether farmers in their areas utilise any $\mathrm{CA}$ techniques as part of their farming practices. A large number of these extension officers $(73.3 \%)$ specified that the farmers they provide extension to do employ CA practices. The extension officers highlighted various techniques of CA which can be seen in Figure 7. One of the issues that limits the incorporation of CA techniques, especially minimum or no-till planting, is the availability of planters to the emerging farmers, as it is specialised and expensive. The extension officers indicated that the lack of availability of CA implements at the various mechanisation centres hampers emerging farmers to employ these practices. More than $63 \%$ of extension officers indicated that the proper implements were not available at the mechanisation centres to incorporate CA techniques through planting practices. This not only impacts the productivity yields of the emerging farmers, but also the conservation of natural resources, especially the fertility of soil and preservation of water availability. 


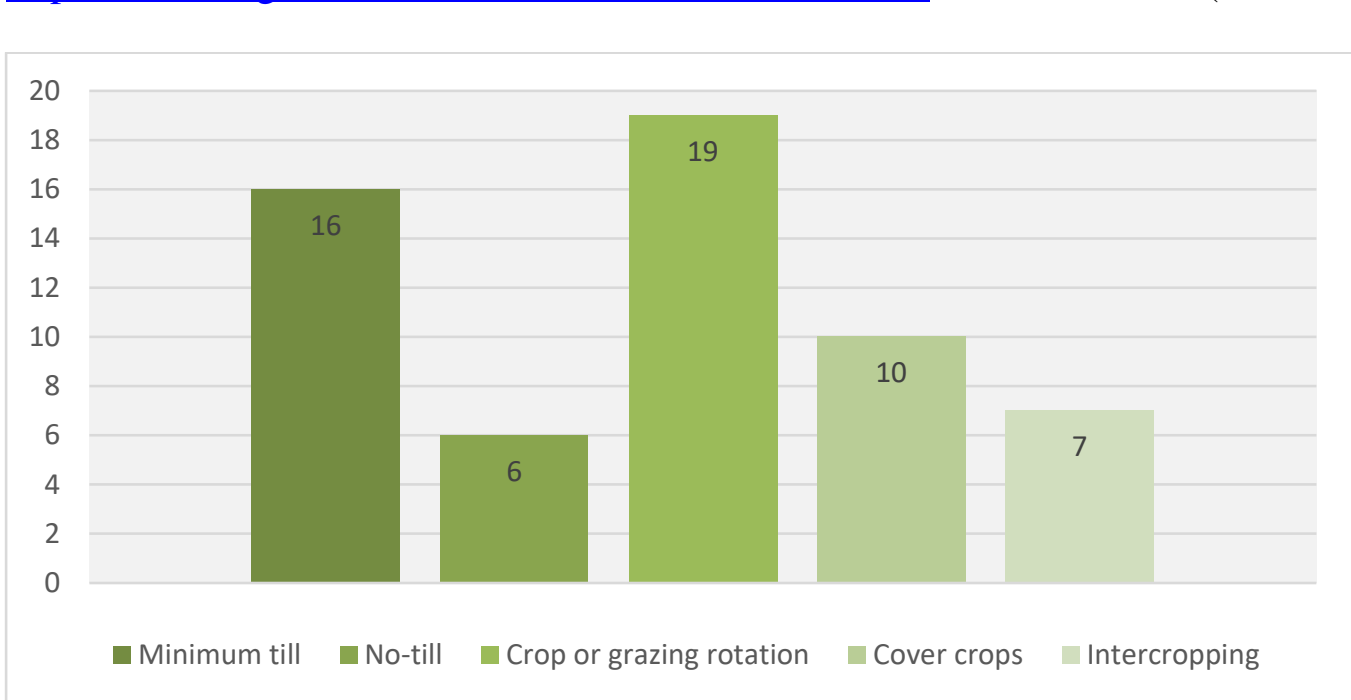

Figure 7: CA practices employed by emerging farmers

\subsection{Perceived effectiveness of the mechanisation programme}

Overall, it was investigated whether the implementation of the mechanisation programme was effective from the perspective of farmers and extension officers. Many farmers felt it was a good programme that can assist emerging farmers as many do not have access to implements. The farmers who have access to mechanisation centres, however, also indicated that more suitable implements should be stationed at the mechanisation centres, that would correspond to the farmers' needs with regards to the type of farming. Furthermore, a large number of farmers indicated that the mechanisation centres are not available in their areas and felt that it would significantly affect the productivity of the farmers in a positive manner if it were accessible in their areas. Extension officers mainly felt that the mechanisation programme was a good initiative, but at the same time also felt that there were issues that must be resolved to make its implementation more effective. The issues referred to by extension officials are mainly management issues, social conflicts within the communities, as well as the same issue raised by farmers, which was that the number of implements and its specifications were not sufficient or relevant to address the needs of the farmers in the districts.

In order to make the mechanisation centres more effective, many farmers indicated that relevant implements should be available depending on the type of agricultural activities that are practised in the specific areas. Another factor that was raised by the majority of the farmers was that management of the centres should be improved and personnel should be properly trained. Finally, many farmers raised the issue that the mechanisation programme should be more widespread as several farmers did not have access to the benefits provided by the mechanisation centres due to its proximities.

Extension officers mentioned that proper planning and management should be put in place and regulations should be drawn up and be adhered to during implementation of the mechanisation centres. Several of the extension officers also indicated that there was a lack of tractor and implement operators and training should be provided to ensure that implements are properly operated and available when needed. As the extension officers that took part in the study were from various districts in the Western Cape, many of them indicated that more mechanisation centres should be established, as many of the farmers they provide extension services to were unable to benefit from the existing mechanisation programme due to distance. Furthermore, 
the extension officers also echoed the suggestions from farmers who indicated that more implements should be available, and that the implements should correspond to the various commodities produced in specific areas. A number of extension officers who practice in dryland grain areas further mentioned that $\mathrm{CA}$ implements should be made available to grain farmers, as it does not only impact the farmer's productivity, but also assists with protection of resources.

Moreover, farmers were asked what challenges they had in their farming enterprises before the implementation of the mechanisation programme. A number of farmers indicated that they had challenges with funding to expand their enterprises with regards to inputs and infrastructure, however, the majority indicated that the high costs of buying or even hiring of tractors or implements or making use of contractors was a major setback to develop and farm sustainably. When extension officers were questioned about the challenges that emerging farmers in their regions encountered, they indicated that the main issue was lack of resources. This challenge included insufficient land availability, the inability to utilise farming land to its potential due to a lack of implements to cultivate, as well as decreased profits due to planters and harvesters not being available during the optimum planting and harvesting periods.

As indicated under the role of the mechanisation programme in the development of emerging farmers, $83.9 \%$ of farmers indicated that they use various types of implements including tractors, planters, plough and harvesters, while $93.3 \%$ of extension officers indicated that the farmers they serve also make use of implements. However, only approximately half of the farmers actually own implements and thus these emerging farmers require assistance to access implements. They indicated that they hire from private companies and other farmers, but those who have access to mechanisation centres make use of the implements supplied by these centres. It was highlighted that $93.5 \%$ of farmers and $96.7 \%$ of extension officials were aware of the mechanisation programme, even though a small percentage $(31 \%)$ of farmers specified that implements were suitable and available if needed. About half $(53.3 \%)$ of the extension officers indicated the same and the various reasons are indicated in Figure 6.

Various mechanisation centres are available in the Overberg and Eden Districts, where 11 projects are in the Overberg District and 20 projects are in the Eden District, with 12 mechanisation centres shared between these two districts. This shows that there is still a lack of mechanisation centres to fulfil the needs of emerging farmers in these two districts with regards to implement availability as the number of emerging farmers in these areas exceed the available implements and the farmers are also unable to access centres because of distance. Managers, farmers and extension officers alike indicated that, except for availability, the suitability of implements must also be investigated as proper implements for particular cultivation practices are not always available.

As previously mentioned, $45 \%$ of farmers indicated that the mechanisation programme aided their agricultural development, but many of the farmers that participated in the study indicated that they did not have access to the mechanisation centres. Furthermore, 54\% of extension officers indicated that the mechanisation programme is effective, but also specified that the lack of mechanisation centres in many areas may be reflective of the low percentage encountered during the study, as many of the farmers for which they provide extension services to did not have access to the mechanisation centres. 


\section{CONCLUSION AND RECOMMENDATIONS}

\subsection{Conclusion}

With regards to the effective implementation of the mechanisation programme, $93.5 \%$ of emerging farmers indicated that they were aware of the programme, and while the majority of the farmers feel that it is a good programme to assist them, they feel that the implementation of the mechanisation programme needs to be improved upon to be fully effective. The farmers felt that more mechanisation centres should be established to fulfil the needs of the farmers, as many of them do not have access to implements provided. The extension officers echoed this sentiment, as only $53.3 \%$ of them indicated that the mechanisation programme and its centres were effective to assist farmers in their respective areas.

In terms of whether the implementation of the mechanisation programme has assisted with the development of emerging farmers, only $45,2 \%$ of the farmers indicated that the programme has helped in their farming enterprises. However, many of the farmers that took part in the study did not have direct access to the mechanisation centres, thus the outcome of this question may not be a true reflection of the actual impact the centres have had on the production of the farmers. In addition, 53.3\% of extension officers indicated that the mechanisation centres have been able to address the challenge of mechanisation shortage in the emerging farmer sector. Thus, half of the extension officers feel that emerging farmer development has been positively impacted through the implementation of this programme. Another issue that was raised by both the farmers and extension officers is that a reason for the decreased effectiveness of the mechanisation programme is the availability and type of implements that are not suitable for the various commodities practised in the respective districts. The majority of farmers indicated that they do not feel that the implements are available or suitable when needed, and this finding may also have impacted the farmers' previously low indication of the mechanisation programmes' effectiveness. Extension officers also felt that the type, number and specifications of implements are not always met to address the need of the farmers.

\subsection{Recommendations}

It can be seen from the findings of this study that mechanisation has a considerable impact on the productivity of many emerging farmers in the agricultural sector. While the impact on those farmers who have access to mechanisation centres is mostly positive, it can also be seen that the implementation of the mechanisation programme has a few issues that need to be addressed. One of the issues that should be investigated in order to ensure better implementation of the programme is the distribution of proper and sufficient amounts of implements at the mechanisation centres. This can only be achieved if the farmers' mechanisation needs specific to their location is taken into account by investigating the type of commodities being farmed and the number of farmers that require mechanisation. Farmers should be consulted before mechanisation centres are established or new implements are delivered to centres. Furthermore, proper policies should be put in place in order to lead implementing agencies and managers of mechanisation centres to ensure that no management related issues could negatively affect farmers and their practices. The employment of these measures could lead to more effective implementation of the mechanisation programme, which would ultimately result in an increase in the development of emerging farmers with regards to their agricultural enterprises. 


\section{REFERENCES}

ANDERSSON, J.A. \& D'SOUZA, S., 2014. From adoption claims to understanding farmers and contexts: A literature review of Conservation Agriculture (CA) adoption among smallholder farmers in southern Africa. Agric. Ecosyst. Environ., 187:116-132.

BROWN, L.R., 2012. Land reform in relation to the economic participation of youth in agriculture in South Africa. Halfway House: National Youth Development Agency.

CORBEELS, M., DE GRAAFF, J., NDAH, T.H., PENOT, E., BAUDRON, F., NAUDIN, K., ANDRIEU, N., CHIRAT, G., SCHULER, J., NYAGUMBO, I. \& RUSINAMHODZI, L., 2014. Understanding the impact and adoption of conservation agriculture in Africa: A multi-scale analysis. Agric. Ecosyst. Environ., 187:155-17.

DELGADO, C., ROSEGRANT, M., STEINFELD, H., EHUI, S. \& COURBOIS, C., 2001. Livestock to 2020: The next food revolution. Outlook Agric., 30(1):27-29.

DEPARTMENT OF AGRICULTURE, FORESTRY AND FISHERIES (DAFF), 2013. Mechanisation programme \& tractor allocation: National Department briefings. Available from: https://pmg.org.za/committee-meeting/15492/

HOBBS, P.R., 2007. Conservation agriculture: What is it and why is it important for future sustainable food production? J. Agric. Sci., 145(2):127.

HOUMY, K., CLARKE, L.J., ASHBURNER, J.E. \& KIENZLE, J., 2013. Agricultural mechanization in Sub Saharan Africa: Guidelines for preparing a strategy. Rome: Food and Agriculture Organization of the United Nations.

MOLOI, M.J., 2010. A comparison of socioeconomic characteristics that determine the farm income of emerging livestock and horticultural farmers in South Africa. PhD Thesis, University of Limpopo.

MREMA, G., SONI, P. \& ROLLE, R., 2014. A regional strategy for sustainable agricultural mechanization: Sustainable mechanization across agri-food chains in Asia and the Pacific region. RAP Publication, 24:74.

NATIONAL DEPARTMENT OF AGRICULTURE (NDA), 2007. A national review of the comprehensive agricultural support programme. Available from: http://www.participation.org.za/docs/CASPReviewMarch2007.pdf

RAI, M., REEVES, T.G., PANDEY, S. \& COLLETTE, L., 2011. Save and grow: A policymaker's guide to sustainable intensification of smallholder crop production. Rome: FAO.

SENYOLO, G.M., CHAMINUKA, P., MAKHURA, M.N. \& BELETE, A., 2009. Patterns of access and utilization of output markets by emerging farmers in South Africa: Factor analysis approach. Afr. J. Agric. Res., 4(3):208-214.

SIMALENGA, T.E., JOUBERT, B \& HANEKOM, D., 2003. Farm mechanization in South Africa. A country study report.

SIMS, B., HILMI, M. \& KIENZLE, J., 2016. Agricultural mechanisation. A key input for SubSaharan African smallholders. Integrated Crop Management. Rome: FAO. 
S. Afr. J. Agric. Ext.

Vol. 47 No. 2, 2019: 58 - 71

http://dx.doi.org/10.17159/2413-3221/2019/v47n2a503
Bastian, Swanepoel, Van Niekerk

(License: CC BY 4.0)

THIERFELDER, C., MWILA, M. \& RUSINAMHODZI, L., 2013. Conservation agriculture in eastern and southern provinces of Zambia: Long-term effects on soil quality and maize productivity. Soil Tillage Res., 126:246-258.

WESTERN CAPE GOVERNMENT (WCG), 2015a. Socio-Economic profile Overberg District Municipality. Western Cape Government. Available from: https://www.westerncape.gov.za/assets/departments/treasury/Documents/Socioeconomicprofiles/2016/OverbergDistrict/dc03_overberg_district_2016_socioeconomic_profile_seplg. Pdf

WESTERN CAPE GOVERNMENT (WCG), 2015b. Socio-Economic profile Eden District Municipality. Western Cape Government. Available from: https://www.westerncape.gov.za/assets/departments/treasury/Documents/Socioeconomic-profiles/2016/Eden-District/dc04_eden_district_municipality_2016_socioeconomic_profile_sep-lg.pdf 
